\title{
LIII. On retardation of chemical action
}

\author{
John J. Hood B.Sc. Assoc. R.S.M.
}

To cite this article: John J. Hood B.Sc. Assoc. R.S.M. (1882) LIII. On retardation of chemical action, Philosophical Magazine Series 5, 13:83, 419-423, DOI: $10.1080 / 14786448208627207$

To link to this article: http://dx.doi.org/10.1080/14786448208627207

$$
\text { 册 Published online: } 28 \text { Apr } 2009 .
$$

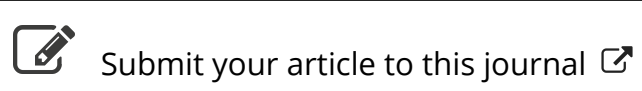

\footnotetext{
Џ Article views: 2
}

Q View related articles $\sqsubset$ 
ing to any wire,

and therefore

$$
\mathrm{E} d t=p^{\prime}
$$

Now for each wire

$$
\mathrm{E}_{1}=\mathrm{E}_{2}=\ldots=\mathrm{E}_{n} \text {. }
$$

$$
\frac{d p}{d t}=\mathrm{E}-\mathrm{R} \dot{q}
$$

where $\mathrm{R}$ is the resistance in the wire. Ultimately, when the motion becomes steady, which it does generally in a very short time,

and therefore

$$
\frac{d p}{d t}=0
$$

But

$$
\mathrm{E}=\mathrm{R} \dot{q}
$$

therefore

$$
\mathrm{E}_{1}=\mathrm{E}_{2}=\ldots=\mathrm{E}_{n} \text {; }
$$

$$
\mathrm{R}_{1} \dot{q}_{1}=\mathrm{R}_{2} \dot{q}_{2}=\ldots=\mathrm{R}_{n} \dot{q}_{n}
$$

and therefore $\Sigma \mathrm{R} \dot{q}^{2}$, or the heat generated in the wires per unit of time, is minimum, given $\Sigma \dot{q}$.

This is the distribution according to Ohm's law, which thus appears as an analytical consequence of Thomson's theorem.

LIII. On Retardation of Chemical Action. By JонN J. Hood, B.Ś., Assoc. R.S.M.*

TN two former papers published in this Journal $\dagger \mathrm{I}$ have 1 given the results of a series of experiments on the rate of oxidation of ferrous sulphate by potassic chlorate, and showed that the course of the reaction for equivalent quantities of the substances is represented by the equation $y(a+t)=b$; the variables being the amount of unoxidized iron expressed in cubic centimetres of a solution of potassic permanganate, and time elapsed from a fixed point in the reaction. This equation is established on the supposition that the products formed have no influence on the rate at which the oxidation goes on ; but when an experiment was continued for a comparatively long period, or till about 80 per cent. and upwards of the oxidation had taken place, a small and ever increasing difference was apparent between the calculated and observed variables, indicating a retardation which was due, without doubt, to the products of the reaction.

The present paper contains the results of a series of experiments made to investigate this retarding effect, in a general

* Communicated by the Author.

† Phil. Mag. [5] vi. p. 371 ; viii. p. 121. 
way, by employing such salts as could not influence the oxidation of the iron by any process of double decomposition.

A solution (about 8 litres) of ferrous sulphate and hydric sulphate was prepared from pure materials and preserved in a large glass jar, arranged in such a way that any required quantity of the solution could be siphoned off, while an atmosphere of coal-gas was always maintained inside the jar. This solution contained in 100 cubic centim.

$$
\begin{aligned}
& 3.1416 \text { grams ferrous iron, } \\
& .038 \text { gram ferric iron, } \\
& 11.84 \text { grams free hydric sulphate. }
\end{aligned}
$$

The solution of potassic chlorate contained in 100 cubic centim. 1.933 gram, 10 cubic centim. being the amount required to oxidize the iron in $16 \cdot 86$ cubic centim. of the ferrous sulphate solution. The method of performing the experiments was the same as has been already described in my former papers.

Each experimental solution consisted of 16.86 cubic centim. of the iron solution or $5296 \mathrm{gram} \mathrm{Fe}^{\prime \prime}$, and $1.996 \mathrm{gram}$ free $\mathrm{H}_{2} \mathrm{SO}_{4}$, together with the requisite amount of the salt whose retarding effect was to be determined, the total volume being made up to 250 cubic centim. with distilled water.

The salts employed were purified from all traces of iron and chlorides, dissolved in distilled water, and the strengths of the solutions determined by double estimations of base and acid.

The flasks containing the experimental solutions were placed in a water-bath, usually six at one time, 10 cubic centim. of the chlorate solution run into each, and the amount of oxidation that had taken place after the lapse of various intervals of time determined by permanganate. From two observations of the amount of unoxidized iron and time, the constants in the equation $y(a+t)=b$ were calculated, three minutes after the addition of the chlorate being taken in every case as the point $t=0$.

As $b$ in the above equation is inversely proportional to the rate of change, or

$$
\frac{d y}{d t}=-\frac{y^{2}}{b}
$$

by a comparison of its values for a series of experiments, in which other conditions being the same except the amount or kind of salt added, with its value for a blank experiment, or that in which no retarding agent is present, a measure of the effect is obtained; these ratios multiplied by 100 are given in Table II.

To determine the equation for the blank as accurately as possible, twenty-four experiments were made, in four batches 
of six each, at various times during the course of the work, which lasted about two weeks, the first batch at the commencement and the fourth at the finish. The mean values obtained were:-

$$
\left.\begin{array}{rr}
a . & b . \\
113 \cdot 8 & 1113 \cdot 8 \\
112 \cdot 9 & 1112 \cdot 5 \\
112 \cdot 4 & 1110 \cdot 8 \\
113 \cdot 0 & 1115 \cdot 7
\end{array}\right\} \text { temp. } 21^{\circ} \mathrm{C} .
$$

or the equation for the blank experiment,

$$
y(113 \cdot() 2+t)=1113 \cdot 2 \text {. }
$$

The following Table contains the mean values for these same constants from two and, in some cases, four experiments, and the weight (calculated as anhydrous) of the various salts present in each:-

Table I. Temp. $21^{\circ} \mathrm{C}$.

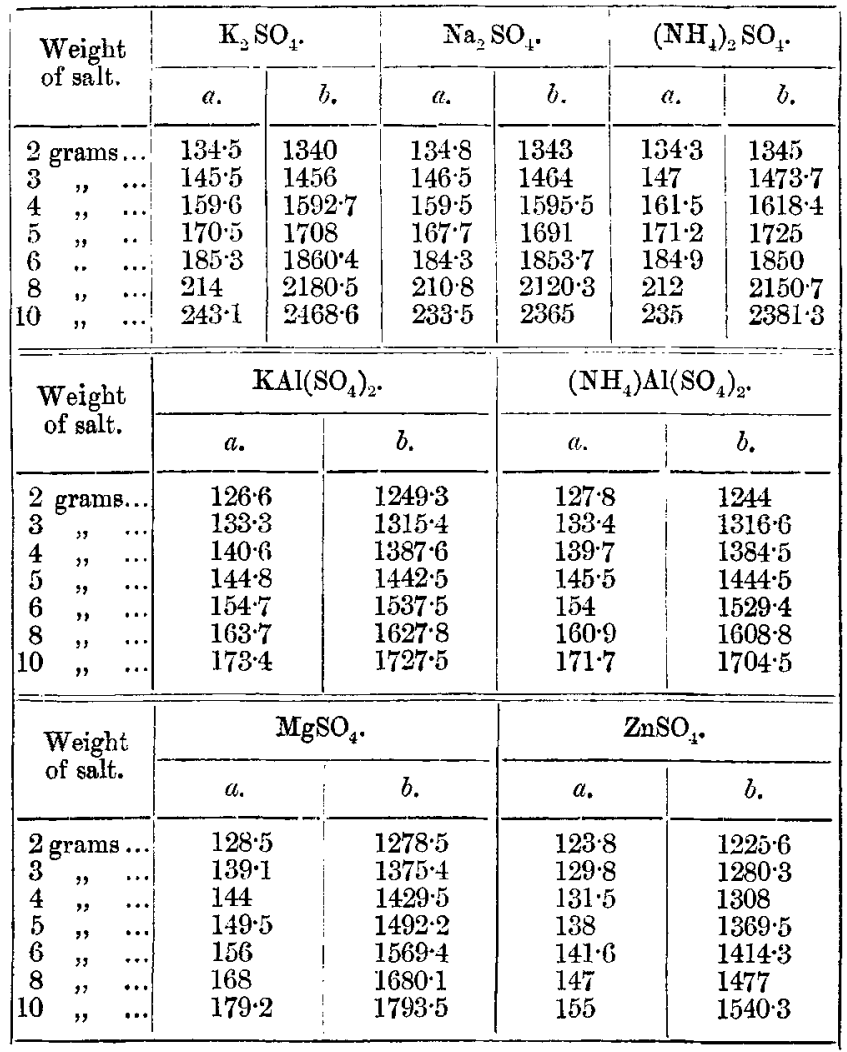


Taking the value of $b$, or $1113 \cdot 2$, for the blank experiment as equal to 100 , and expressing the corresponding values of this quantity contained in the above Table in terms of it, the numbers contained in the following Table are obtained; they; in point of fact, represent the number of minutes required to oxidize the iron in each solution from $y^{\prime}$ to $y^{\prime \prime}$, the time required to perform the same amount of oxidation in the blank experiment being 100 minutes.

TABLE II.

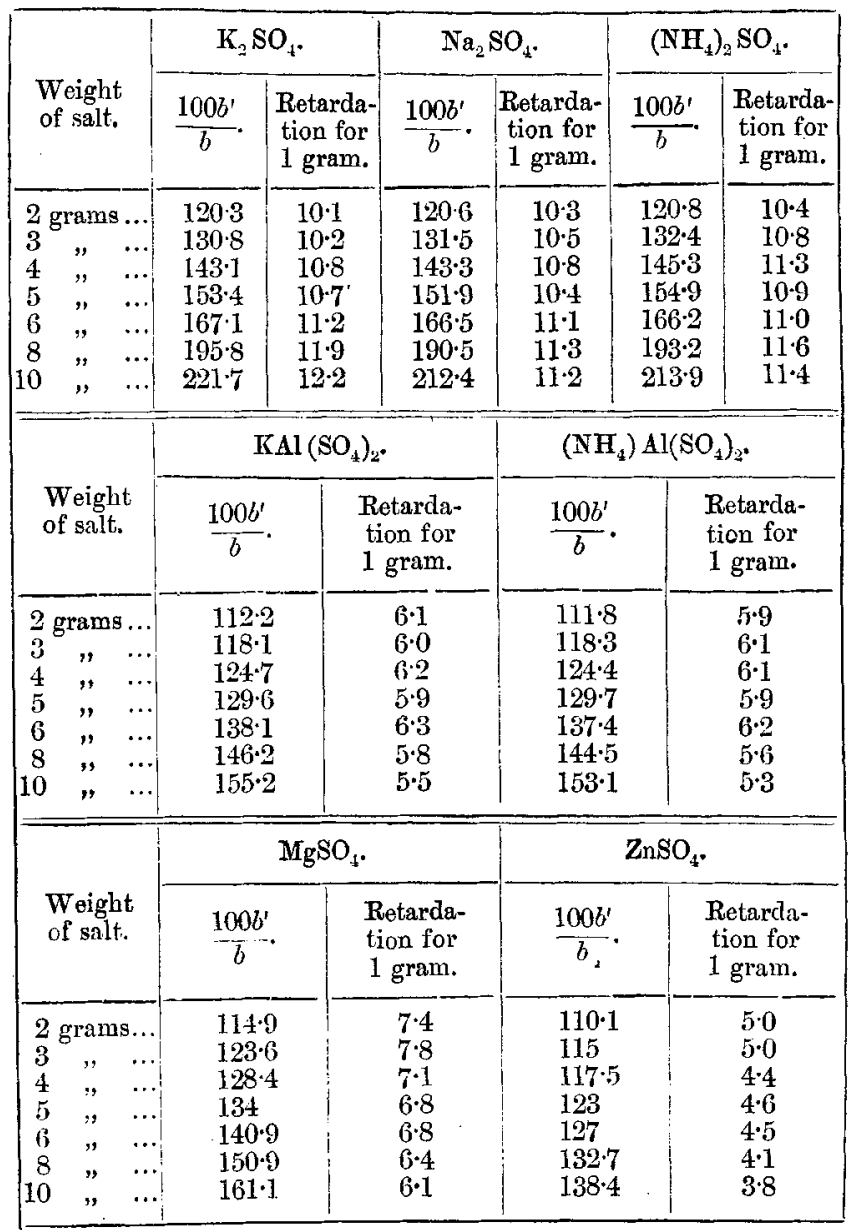

From the numbers contained in Table II., it will be seell that the retardation in the rate of oxidation of ferrous sulphate 
On the supposed Helical Path of the Electric Current. 423

by potassic chlorate is proportional to the weight of the chemically inactive salt present, and that the amount of this retardation is the same for equal weights of those salts which more or less resemble each other constitutionally. This is seen to hold for the sulphates of the alkaline metals and ammonium, and also for the two alums; but in the case of the sulphates of zinc and magnesium the difference in their effects is too considerable to permit of their being classed together, in a dynamical sense, however much they may resemble each other statically. The fact that equal weights of the alkaline sulphates or the alums produce equal effects, shows that the retardation produced by a single molecule of those salts which belong to the same group is proportional to its weight.

Mills and Walton have shown * that, in the formation of ammonia by the action of zine amalgam on potassic nitrate, the presence of sodic or potassic sulphate produces an acceleration in the reaction, and that equal weights of the two salts have, as nearly as possible, equal working effects.

My best thanks are due to Dr. Frankland, in whose laboratory the above experiments were made.

LIV. Note on the supposed Helical Path of the Electric Current in longitudinally Magnetized Conductors. By J. A. Ewrag, B.Sc., F.R.S.E., Professor of Mechanical Engineering in the University of Tokio, Japan †.

TN a paper entitled "Molecular Magnetism," read before 1. the Royal Society on May 19, Prof. Hughes describes experiments which have led him to the conclusion " that the path of an electric current through an iron or steel wire is that of a spiral." Prof. Hughes mentions that the wires experimented on were never entirely free from longitudinal magnetization to begin with, and that when they were further magnetized the effects observed, which formed the ground of the conclusion just quoted, were greatly increased. It may fairly be assumed that these effects were in all cases due to the presence of longitudinal magnetism in the wires.

The object of this note is to point out that the experimental results obtained by Prof. Hughes admit of anothor interpretation than that which he has given them, and at the same time to suggest a method of determining whether there is, or is not, any such helical quality in the path of the current as he has inferred.

* Proc. Roy. Soc. 1879.

$\dagger$ Communicated by the Author. 